\title{
Tumour-associated fibroblasts
}

\section{contribute to neoangiogenesis in human parathyroid neoplasia}

\author{
C Verdelli, L Avagliano ${ }^{1}$, P Creo $^{2}$, V Guarnieri ${ }^{3}$, A Scillitani ${ }^{4}$, L Vicentini ${ }^{5}$, G B Steffano ${ }^{6}$, \\ E Beretta $^{7}$, L Soldati ${ }^{8}$, E Costa, A Spada ${ }^{9}$, G P Bulfamante ${ }^{1}$ and S Corbetta ${ }^{10}$ \\ Laboratory of Molecular Biology, IRCCS Policlinico San Donato, San Donato Milanese, Milan, Italy \\ 1 Department of Human Pathology, San Paolo Hospital, University of Milan, Milan, Italy \\ ${ }^{2}$ Laboratory of Stem Cells for Tissue Engineering, IRCCS Policlinico San Donato, San Donato Milanese, Milan, Italy \\ ${ }^{3}$ Medical Genetics, and ${ }^{4}$ Endocrinology Unit, IRCCS Hospital Casa Sollievo Sofferenza, San Giovanni Rotondo, \\ Foggia, Italy \\ ${ }^{5}$ Endocrine Surgery, IRCCS Fondazione Cà Granda Ospedale Maggiore Policlinico, Milan, Italy \\ ${ }^{6}$ Surgery Unit, IRCCS Policlinico San Donato, San Donato Milanese, Milan, Italy \\ ${ }^{7}$ Surgery Unit, IRCCS Ospedale San Raffaele, Milan, Italy \\ ${ }^{8}$ Department of Health Sciences, and ${ }^{9}$ Endocrinology and Diabetology Unit, Department of Clinical and Community \\ Sciences, IRCCS Fondazione Cà Granda Ospedale Maggiore Policlinico, University of Milan, Milan, Italy \\ ${ }^{10}$ Endocrinology and Diabetology Unit, Department of Biomedical Sciences for Health, IRCCS Policlinico \\ San Donato, University of Milan, Via Morandi 30, 20097 San Donato Milanese, Milan, Italy
}

Correspondence should be addressed to S Corbetta

Email

sabrina.corbetta@unimi.it

\begin{abstract}
Components of the tumour microenvironment initiate and promote cancer development. In this study, we investigated the stromal component of parathyroid neoplasia. Immunohistochemistry for alpha-smooth muscle actin ( $\alpha$-SMA) showed an abundant periacinar distribution of $\alpha$-SMA ${ }^{+}$cells in normal parathyroid glands $(n=3)$. This pattern was progressively lost in parathyroid adenomas (PAds; $n=6$ ) where $\alpha$-SMA ${ }^{+}$cells were found to surround new microvessels, as observed in foetal parathyroid glands $(n=2)$. Moreover, in atypical adenomas $(n=5)$ and carcinomas $(n=4), \alpha-\mathrm{SMA}^{+}$cells disappeared from the parenchyma and accumulated in the capsula and fibrous bands. At variance with normal glands, parathyroid tumours $(n=37)$ expressed high levels of fibroblast-activation protein $(F A P)$ transcripts, a marker of tumour-associated fibroblasts. We analysed the ability of PAd-derived cells to activate fibroblasts using human bone-marrow mesenchymal stem cells (hBM-MSCs). PAd-derived cells induced a significant increase in FAP and vascular endothelial growth factor A (VEGFA) mRNA levels in co-cultured hBM-MSCs. Furthermore, the role of the calcium-sensing receptor (CASR) and of the CXCL12/CXCR4 pathway in the PAd-induced activation of hBM-MSCs was investigated. Treatment of co-cultures of hBM-MSCs and PAd-derived cells with the CXCR4 inhibitor AMD3100 reduced the stimulated VEGFA levels, while CASR activation by the R568 agonist was ineffective. PAd-derived cells co-expressing parathyroid hormone (PTH)/CXCR4 and PTH/CXCL12 were identified by FACS, suggesting a paracrine/autocrine signalling. Finally, CXCR4 blockade by AMD3100 reduced PTH gene expression levels in PAd-derived cells. In conclusion, i) PAd-derived cells activated cells of mesenchymal origin; ii) PAd-associated fibroblasts were involved in tumuor neoangiogenesis
\end{abstract}

\section{Key Words}

- tumour-associated fibroblasts

- parathyroid

- VEGFA

- CXCR4

- SDF1/CXCL12

- PTH http://erc.endocrinology-journals.org DOI: 10.1530/ERC-14-0161
(C) 2015 Society for Endocrinology Printed in Great Britain
Published by Bioscientifica Ltd. 
and iii) CXCL12/CXCR4 pathway was expressed and active in PAd cells, likely contributing to parathyroid tumour neoangiogenesis and PTH synthesis modulation.

\section{Introduction}

Primary hyperparathyroidism, the third most common endocrine disorder, frequently complicated by bone and renal involvement and increased cardiovascular mortality is caused by parathyroid neoplasia. Parathyroid tumours display different features spanning throughout benign adenomas, hyperplasia, atypical adenomas and the rare carcinomas. As far as the pathogenetic mechanisms of parathyroid tumourigenesis are concerned, attention has been focused so far on the proliferation of epithelial cells, although parathyroid neoplasia have a stromal component that is increased in atypical and carcinomatous lesions, as observed in most common cancers. The tumour microenvironment is composed by a variety of vascular and stromal cell types. Indeed, previous studies focusing on microvessels density demonstrated increased angiogenesis in parathyroid proliferative lesions compared with normal glands (Garcia de la Torre et al. 2004, Viacava et al. 2006).

Tumour microenvironment is emerging as an important target for cancer therapy. Fibroblasts within the tumour stroma are critically involved in promoting tumour growth and angiogenesis through secretion of soluble factors, synthesis of extracellular matrix and direct cell-cell interaction. Tumour-associated fibroblasts (TAFs) act by inducing the expression of factors, such as the stromalderived factor 1 (SDF1, also called CXCL12), as well as myofibroblast markers, including alpha-smooth muscle actin $(\alpha$-SMA), vimentin and fibroblast surface protein. SDF1 signalling via its cognate receptor, chemokine (C-X-C motif) receptor 4 (CXCR4) stimulates tumour cells proliferation and neoangiogenesis by recruiting circulating endothelial progenitor cells into the tumour stroma (Kojima et al. 2010). TAFs are thought to originate from local existing fibroblasts, recruited bone marrow-derived mesenchymal stem cells or, in some cases, epithelial-to-mesenchymal transition (De Wever et al. 2008, Polanska \& Orimo 2013).

In this study focused on parathyroid neoplasia microenvironment, i) we identified cells displaying some features of TAFs, likely involved in neoangiogenesis, ii) we provided data supporting the ability of tumour parathyroid cells to activate mesenchymal cells and iii) we tested the effect of the CXCR4 antagonist AMD3100 on angiogenesis and parathyroid hormone (PTH) expression in parathyroid neoplasia.

\section{Materials and methods}

\section{Samples collection}

Formalin-fixed paraffin-embedded (FFPE) sections from three normal parathyroid glands accidentally removed during thyroid surgery of normocalcaemic patients, 15 parathyroid tumours (four parathyroid carcinomas (PCas), five atypical parathyroid adenomas (PAts) and six typical parathyroid adenomas (PAds)) from patients with sporadic primary hyperparathyroidism and two foetal (of 19 and 25 weeks of gestation) parathyroid glands were collected and analysed by immunohistochemistry (IHC). Additional FFPE sections from four PCas, one PAts and 17 PAds were collected for RNA analyses by RT-PCR. Tissues from foetuses of gestational ages 19 and 25 weeks were collected as previously described (Corbetta et al. 2005). Briefly, foetuses were collected after legal voluntary termination of pregnancy for maternal psychiatric disorders, according to the Italian legislation that allows termination of pregnancy for medical reasons up to 25 weeks of gestation. In all cases, informed consent of the mother was obtained before procurement of the tissues, in accordance with the guidelines outlined by the San Paolo Institute Ethics Committee. Histological classification for parathyroid atypical adenomas and carcinomas was established according to WHO published guidelines (Bondenson et al. 2004) and sampled as described previously (Corbetta et al. 2010).

Fresh tissue samples from 25 PAds of patients with sporadic primary hyperparathyroidism were collected for further investigations. Tissues removed were in part placed in a sterile medium for cell culture and in part snap frozen in liquid nitrogen and stored at $-80^{\circ} \mathrm{C}$ until analysis. The study was approved by the local ethical committee and informed consent was obtained from all patients.

\section{Immunohistochemistry}

Both adult and foetal samples were fixed in 10\% buffered formalin followed by conventional processing and embedded in paraffin. Four-micrometer-thick sections were cut and stained with haematoxylin and eosin for

Published by Bioscientifica Ltd. 
histopathological assessment. The tissue sections were then incubated with primary antibody to $\alpha$-SMA (1:200 dilution; ab5694, Abcam, Cambridge, UK). The stained sections were imaged by the digital slide scanner NanoZoomer 2.0 (Hamamatsu Photonics Italy S.r.1., Arese, Italy).

\section{Culture of PAd-derived explants and cells}

The samples from PAds were cut into fragments $<1 \mathrm{~mm}^{3}$, washed and partially digested with collagenase type 1 (Worthington, Lakewood, NJ, USA) at a concentration of $1 \mathrm{mg} / \mathrm{ml}$ for $90 \mathrm{~min}$. These tissue fragments, termed parathyroid explants, were cultured on fibronectin-coated dishes and on dishes without coating. The explants derived from human PAds were routinely grown at $37^{\circ} \mathrm{C}, 5 \% \mathrm{CO}_{2}$ in DMEM supplemented with $10 \%$ foetal bovine serum (FBS), $2 \mathrm{mmol} / \mathrm{l}$ glutamine and $100 \mathrm{U} / \mathrm{ml}$ penicillin-streptomycin. During the 1st week of growth, a layer of fibroblasts emerges from the parathyroid explants.

Parathyroid single cells were isolated by digestion of tissue fragments with collagenase type 1 at the concentration of $2 \mathrm{mg} / \mathrm{ml}$ for $90 \mathrm{~min}$. After digestion, tissue fragments were filtered with a cell strainer $(100 \mathrm{~mm}$ Nylon, BD Falcon, San Jose, CA, USA) and collected cells were routinely grown in the same condition of explants, as described previously.

\section{Co-culture of human bone marrow-derived mesenchymal stem cells with PAd-derived cells and explants}

Human bone marrow-derived mesenchymal stem cells (hBM-MSCs) were obtained from bone marrow (BM) samples from healthy subjects donating BM to a sibling for allogenic haematopoietic stem cell transplantation, after obtaining written informed consent. hBM-MSCs were plated on the bottom of six-well plates with sterile inserts (Cell Culture Insert, BD Falcon) in the culture medium. Pore size of the membrane was $0.4 \mu \mathrm{m}$. The cells were grown at $37^{\circ} \mathrm{C}, 5 \% \mathrm{CO}_{2}$ in DMEM low glucose (Glc $1 \mathrm{~g} / \mathrm{l}$; D5546, Sigma-Aldrich) supplemented with 10\% FBS (HyClone, Thermo Scientific, Waltham, MA, USA), $4 \mathrm{mM}$ L-glutamine and $100 \mathrm{U} / 1$ penicillin-100 $\mu \mathrm{g} / \mathrm{l}$ streptomycin (Euroclone, Pero, Italy). When hBM-MSCs were adherent, PAd-derived cells and explants were seeded in the insert at a density of $1 \times 10^{5}$ cells. The co-cultures were incubated with the highly specific chemokine receptor CXCR4 antagonist, AMD3100 (Octahydrochloride; A 5602, Sigma-Aldrich), at the concentration of 1 or $10 \mu \mathrm{g}$ for 5 and 10 days or with the potent selective calcium-sensing receptor (CASR) agonist R568 (Amgen, Inc., Thousand Oaks, CA, USA) at the concentration of $50 \mu \mathrm{M}$. hBM-MSCs were harvested and used for RNA analysis.

\section{RNA extraction}

Total RNA was extracted from FFPE sections of three normal parathyroid glands, 23 PAds, six PAts and eight PCas using All Prep DNA/RNA FFPE kit (Qiagen) according to the manufacturer's protocol. Total RNA from fresh tissue samples (five PAds) and cultured cells was isolated using TRIzol reagent (Invitrogen) and quantified by spectrophotometry at $260 \mathrm{~nm}$ (NANODROP ND-1000 u.v./Vis, Thermo Scientific). DNA contamination was removed by DNase (Life Technologies) treatment.

\section{RT-PCR}

RT was performed using the iScript cDNA Synthesis kit (Bio-Rad) with a starting amount of $300 \mathrm{ng}$ RNA from three normal parathyroid glands, 12 PAds and three PCas. The reaction mix contained an optimised blend of oligo(dT) and random primers. Derived cDNA was amplified with PCR. Specific primers for human $\alpha$-SMA, $S D F 1$, fibroblast-activation protein $(F A P)$, vimentin and $\beta$-actin were designed with Primer3 Software (http://frodo. wi.mit.edu). The PCRs involved an initial denaturation at $94^{\circ} \mathrm{C}$ for $5 \mathrm{~min}$, followed by 35 cycles at $94^{\circ} \mathrm{C}$ for $1 \mathrm{~min}$, exposure to an appropriate annealing temperature $\left(58-62^{\circ} \mathrm{C}\right.$ ) for $1 \mathrm{~min}$, incubation at $72{ }^{\circ} \mathrm{C}$ for $1 \mathrm{~min}$ and a final step at $72^{\circ} \mathrm{C}$ for $5 \mathrm{~min}$. Amplified RT-PCR products were then analysed on $1.5 \%$ agarose gels and visualised using ethidium bromide staining and a camera system (CHEMI DOC XRS, Bio-Rad) and compared with a DNA Molecular Weight Marker (Roche).

\section{Real-time PCR}

Real-time PCR was performed with a StepOne Plus System (Applied Biosystems) using TaqMan gene expression assay following the manufacturer's protocol. All reactions consisted of $1 \mu \mathrm{l}$ of $20 \times$ TaqMan Gene Expression Assay FAM dye-labelled (vascular endothelial growth factor A (VEGFA), Hs000900055_m1; $\alpha$-SMA, Hs00426835_g1; PTH, Hs00757710_1g and CCND1, Hs00765553_m1, Applied Biosystems, Life Technologies), $10 \mu \mathrm{l}$ of $2 \times$ TaqMan Gene Expression MasterMix (Applied Biosystems), $4 \mu \mathrm{l}$ of cDNA (20 ng) in a final reaction volume of $20 \mu \mathrm{l}$. Gene expression was quantified using a comparative $C$ t method, which normalises the $C t$ values to internal

Published by Bioscientifica Ltd. 
housekeeping gene, HMBS and B2M (Hs00609297_m1, HMBS and Hs99999907_m1, B2M), and calculates the relative expression values. The cycling conditions were at $50{ }^{\circ} \mathrm{C}$ for $2 \mathrm{~min}$ and an initial denaturation step at $95^{\circ} \mathrm{C}$ for $10 \mathrm{~min}$, followed by 40 cycles with denaturation at $95^{\circ} \mathrm{C}$ for $15 \mathrm{~s}$ and annealing of probes at $60^{\circ} \mathrm{C}$ for $1 \mathrm{~min}$. Amplification data were collected at this final step. The amplification of $R U N X, P P A R \gamma$ and $A L P$ was carried out with $10 \mathrm{ng}$ of cDNA as template, $0.2 \mu \mathrm{M}$ primers and $1 \mathrm{X}$ iQ Custom SYBR Green Supermix (Bio-Rad) in a $20 \mathrm{ml}$ of final volume. All experiments were repeated for at least three times to ensure the accuracy of results, which were expressed as arbitrary unit.

\section{Immunofluorescence}

PAd-derived cells and explants were fixed in $4 \%$ paraformaldehyde, permeabilised in $0.1 \%$ Triton $\mathrm{X}-100$ and blocked in 1\% BSA-PBS for $2 \mathrm{~h}$. The cells were incubated with primary antibodies, $\alpha$-SMA (F3777, Sigma-Aldrich; 1:500), GCM2 (D-20, Santa Cruz Biotechnologies; 1:100), PTH (BGN/1F8, Santa Cruz Biotechnologies), CD34 (ready to use, Novocastra, Newcastle on Tyne, UK), CASR (antiserum raised in rabbits as described previously (Corbetta et al. 2000)) and CXCR4 (ab2074, Abcam, Cambridge, MA, USA; 1:100); washed thrice in PBS and then incubated with secondary antibodies conjugated with FITC, DyLight549 and Cy3 (Jackson Immuno Research, West Grove, PA, USA; 1:100). Hoechst 33342 (1:500) was used as nuclear stain (blue). As a specificity control, PBS was used instead of primary antibodies to exclude unspecific binding of secondary antibody. The images were obtained by fluorescent microscopy and a digital camera.

\section{Fluorescent-activated cell analysis}

The cells were harvested in suspension with the use of $1 \%$ trypsin digestion with DMEM+10\% FBS neutralisation. Single-cell suspensions were washed twice with ice-cold PBS, blocked in 50\% FBS-PBS for 30 min and fixed in 4\% paraformaldeyde for $20 \mathrm{~min}$ at $4{ }^{\circ} \mathrm{C}$. The cells were permeabilised in $0.5 \%$ Triton $\mathrm{X}-100$ and blocked with a blocking solution (50\% $1 \times$ PBS and 50\% FBS) for $30 \mathrm{~min}$. Then cells were incubated with anti-CXCR 4 and anti-PTH antibodies prepared in $0.5 \%$ Triton X-100-PBS and incubated for $1 \mathrm{~h}$ at $4{ }^{\circ} \mathrm{C}$. After washing with PBS, cells were stained with the appropriate secondary antibodies conjugated with Alexa Fluor 488 (green) or DyLight549 (red) (Jackson Immuno Research; 1:100) for 30 min on ice in the darkness. After three washes with PBS, the cells were analysed on a flow cytometer (Navios, Beckman Coulter, Brea, CA, USA) using Kaluza Software.

\section{Statistical analyses}

Data are expressed as mean \pm s.E.M. When comparing the data from repeated measurements, paired two-tailed Student's $t$-test or one-way ANOVA was used to determine the levels of significance. Statistical differences between percentages were detected by $\chi^{2}$ or Fischer's exact test, as appropriate. A $P$ value of $<0.05$ was considered to be statistically significant.

\section{Results}

\section{Stromal cells in human parathyroid tissues}

Stromal component of normal and neoplastic parathyroid tissues was investigated by focusing on the expression of $\alpha$-SMA that is considered a marker of activated fibroblasts, known as myofibroblasts. Specific immunostaining for $\alpha$-SMA showed that $\alpha$-SMA ${ }^{+}$cells were well represented in the parenchyma of normal parathyroid glands where they were located in the stroma lining the acinar cell structures $(n=3$; Fig. $1 \mathrm{~A}$ and B). In typical PAds $(n=6)$, epithelial tumour cells were negative for $\alpha$-SMA (Fig. 1D, E and F). Intraparenchymal $\alpha$-SMA ${ }^{+}$cells were confined to zones with an acinar pattern of cell proliferation similar to those observed in the normal gland. The zones with a trabecular pattern of cell proliferation were poor of myofibrobasts (Fig. 1G). In PAds $\alpha$-SMA ${ }^{+}$cells surrounded new microvessels, consistent with a possible role in neoangiogenesis (Fig. 1E and F). Interestingly, in human foetal parathyroids (19 and 25 weeks of gestational age), $\alpha$-SMA ${ }^{+}$cells were exclusively found lining blood vessels in formation (Fig. 1C). In PAts $(n=5$; Fig. $1 \mathrm{H}$ and I) and PCas $(n=4$; Fig. 1I, J, K and L), the parathyroid epithelial cells proliferating in sheets were not sustained by $\alpha$-SMA ${ }^{+}$cells. Conversely, $\alpha$-SMA ${ }^{+}$cells were abundantly represented in the stroma of fibrous bands, in the septa departing from the capsula and in the peripheral capsula.

\section{Expression of TAFs-related genes in human parathyroid tissues}

TAFs-related genes mRNA expression, namely $\alpha$-SMA, SDF1 (CXCL12), FAP and vimentin, was detected by RT-PCR in parathyroid samples. While $\alpha$-SMA, SDF1/CXCL12 and vimentin mRNAs were homogeneously expressed almost in all normal and neoplastic tissue samples, FAP was

Published by Bioscientifica Ltd. 

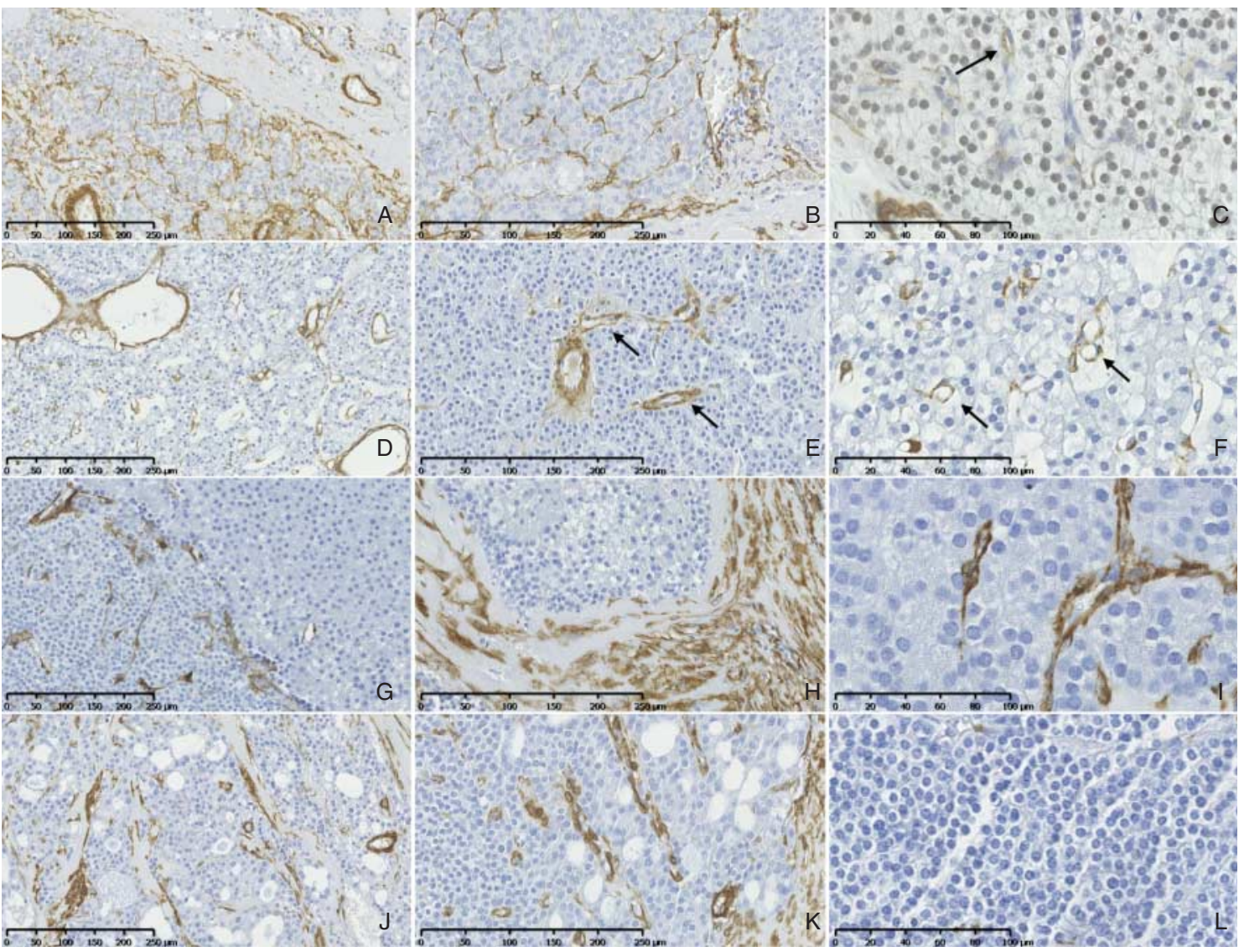

\section{Figure 1}

Stromal component in human parathyroid tissues by $\alpha$-SMA immunostaining. $\alpha$-SMA-specific immunohistochemistry showed a periacinar and perivascular distribution in normal parathyroid glands (A and B); in PAds $(D, E$ and $F), \alpha-S M A^{+}$cells were less abundant in the parenchyma than in normal glands, while they lined neovascular structures (arrows) similar to what observed in the 19-week human foetus (C, arrow). In PAts ( $G, H$ and I), $\alpha$-SMA ${ }^{+}$cells were abundant in the fibrous bands and the capsula; notably, variations in the parenchymal architecture could be observed among

undetectable in normal parathyroid glands, while it was expressed at variable levels in both PAds and PCas (Fig. 2A). Furthermore, quantitative analysis by TaqMan real-time PCR confirmed RT-PCR findings. In particular, FAP transcripts were undetectable in normal parathyroid glands, while the gene was variably expressed in tumours. Interestingly, $F A P$ mRNA levels were significantly increased in PCas $(3.74 \pm 1.16 ; P<0.001)$ compared with PAds $(0.17 \pm 0.07)$ and PAts $(0.04 \pm 0.04)$ (Fig. 2B).

\section{TAFs overgrowth from cultured parathyroid tumour-derived explants}

TAFs from PAd-derived explants were in vitro cultured in the attempt to characterise these cells. The explants are different areas of the same tumour (G). In PCas (J, K and L), $\alpha$-SMA ${ }^{+}$cells were confined to the capsular and subcapsular areas, while they were absent in the parenchyma. (A), (D), (G) and (J) were imaged at $10 \times$ magnification and bars represented $250 \mu \mathrm{M} ;(B),(E),(H)$ and $(K)$ were imaged at $20 \times$ magnification and scale bars represented $250 \mu \mathrm{M}$; (C), (F), $(\mathrm{I})$ and $(\mathrm{L})$ were imaged at $40 \times$ magnification and scale bars represented $100 \mu \mathrm{M}$.

considered as an in vitro 3D fibroblasts-enriched model of cancer. The explants obtained from PAds $(n=5)$ consistently gave rise to outgrowths of cells that comprised foreskin fibroblasts and large spindle-shaped cells, resembling myofibroblasts (Fig. 2C, a and b). Large spindle-shaped fibroblasts showed cytoplasmic filaments immunoreagent with specific anti- $\alpha$-SMA antibody, consistent with myofibroblast feature (Fig. 2C, c and d). The explant culture system was robust, explants survived up to 2 weeks and during this period, cell viability and morphologic characteristics were stable. The explants cultured on fibronectin-coated supports did not differ from those cultured on uncoated supports (data not shown), suggesting that myofibroblasts were not induced by culture support. PAd-derived explants expressed the TAF-related genes

Published by Bioscientifica Ltd. 
A

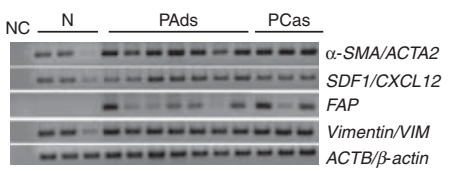

B

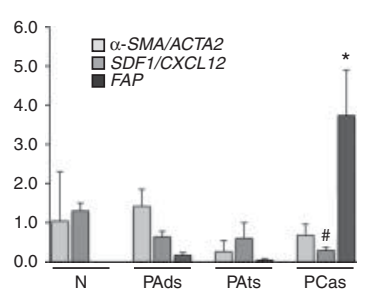

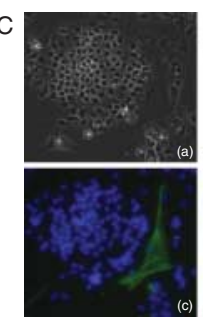

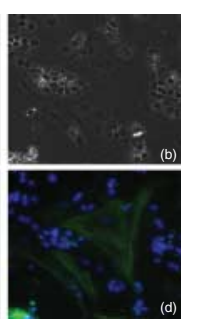

D

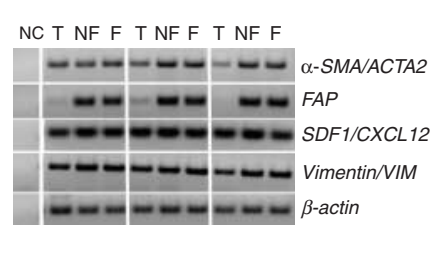

\section{Figure 2}

TAF-specific genes expression in human parathyroid normal and tumour tissues and in PAd-derived explants. (A) Specific gene expression of activated fibroblasts was variably detected in all parathyroid tumours by RT-PCR, while fibroblast-activation protein (FAP) mRNA was expressed only in parathyroid neoplasia. (B) Quantitative analysis by TaqMan real-time PCR of the activated fibroblast genes expression in normal parathyroid glands $(n=3)$, PAds $(n=23)$, PAts $(n=7)$ and PCas $\left(n=9 ;{ }^{*} P=0.001\right.$ vs normal glands; ${ }^{*}<0.05$ vs normal glands and PAds). (C) PAd-derived explants

$\alpha$-SMA, SDF1/CXCL12, FAP and vimentin mRNAs. FAP gene was highly induced by cell culture (Fig. 2D).

\section{PAd-associated myofibroblasts expressed parathyroid- specific transcription factors}

Immunofluorescence (IF) showed that $\alpha-\mathrm{SMA}^{+}$cells did not co-express CASR protein (Fig. 3A, B, C and D), nor PTH (Fig. 3E, F, G and H), while a subset co-expressed the haematopoietic surface marker CD34 (Fig. 3K and L), suggesting the origin from BM stromal cell progenitors. A subset of $\alpha-\mathrm{SMA}^{+}$cells co-expressed GCM2 at nuclear level, a specific parathyroid marker (Fig. 4E, F, G and $\mathrm{H}$ ), and TBX1, an embryonic nuclear transcription factor involved in development of endodermic pharynx (Fig. 4M, N, $\mathrm{O}$ and $\mathrm{P}$ ), suggesting the occurrence of epithelialto-mesenchymal transition.

\section{PAd-derived epithelial cells induced activation of hBM-MSCs}

To test the hypothesis that tumour parathyroid epithelial cells can activate stromal fibroblasts, we performed co-cultures of single cells obtained from PAds with hBMMSCs, which is considered as a model of tumour inducible TAFs. In fact, long-term co-culture of hBM-MSCs with the conditioned medium from different tumour cells has been shown to activate hBM-MSCs to cells expressing markers of myofibroblasts (Mishra et al. 2008). Co-culture of hBMMSCs with PAd-derived explants $(n=4)$ for 5 and 10 days induced significant up-regulation of $F A P$ mRNA expression levels $(0.99 \pm 0.04$ vs $1.86 \pm 0.30$ at 5 days and $2.62 \pm 1.02$ at 10 days; $P=0.04$ ) (Fig. 5A), while $\alpha$-SMA mRNA levels did cultured for 7 days showed a significant overgrowth of fibroblastic cells ( $a$ and $b$ ), with abundance of large spindle-shaped $\alpha$-SMA ${ }^{+}$fibroblasts, resembling myofibroblasts ( $c$ and d). (D) PAd-derived explants cultured for 7 days showed significant increases in FAP mRNA expression both in fibronectin-coated (F) supports and in the absence of fibronectin (NF). T, corresponding tumour sample; SDF1, stromal-derived factor 1; FAP, fibroblast-activation protein; $M$, molecular weight; NC, negative control.

not vary significantly (data not shown). Interestingly, hBM-MSCs FAP mRNA levels were increased by co-culture with PAd-derived single cells $(0.99 \pm 0.04$ vs $2.15 \pm 0.33$ at 5 days and $2.97 \pm 0.64$ at 10 days; $P=0.02$ ), suggesting that tumour parathyroid epithelial cells activated stromal cells.

Co-culture in non-differentiating conditions did not induce hBM-MSCs differentiation as PPAR $\gamma$ or RUNX genes mRNAs were not detected in co-cultured hBM-MSCs (data not shown). Indeed, two out of four PAd-derived cell preparations determined a significant increase in alkaline phosphatase $(A L P)$ mRNA expression levels in hBM-MSCs (data not shown).

\section{PAd-derived parathyroid cells stimulated VEGFA expression in hBM-MSCs}

Activated myofibroblasts were found to surround new microvessels in PAds. We investigated whether PAd-derived cells could induce the expression of the VEGFA gene in hBMMSCs. Co-cultures for 5 days with PAd-derived explants as well as single-cells in normoxic conditions induced a significant increase in VEGFA mRNA expression levels $(2.16 \pm 0.46$-fold in explants and 1.76 \pm 0.31 -fold in single cells vs basal condition levels; $P<0.05)$ that was detected also in long-term cell cultures $(1.92 \pm 0.22$-fold at 10 days and $1.30 \pm 0.13$ at 15 days in explants and $1.53 \pm 0.12$-fold at 10 days and $1.92 \pm 0.22$ at 15 days in single cells) (Fig. 5B).

\section{Effect of CASR activation on PAd-stimulated VEGFA mRNA levels in hBM-MSCs}

We investigated the effect of the potent CASR agonist R568 on VEGFA mRNA levels in hBM-MSCs, as these cells

Published by Bioscientifica Ltd 

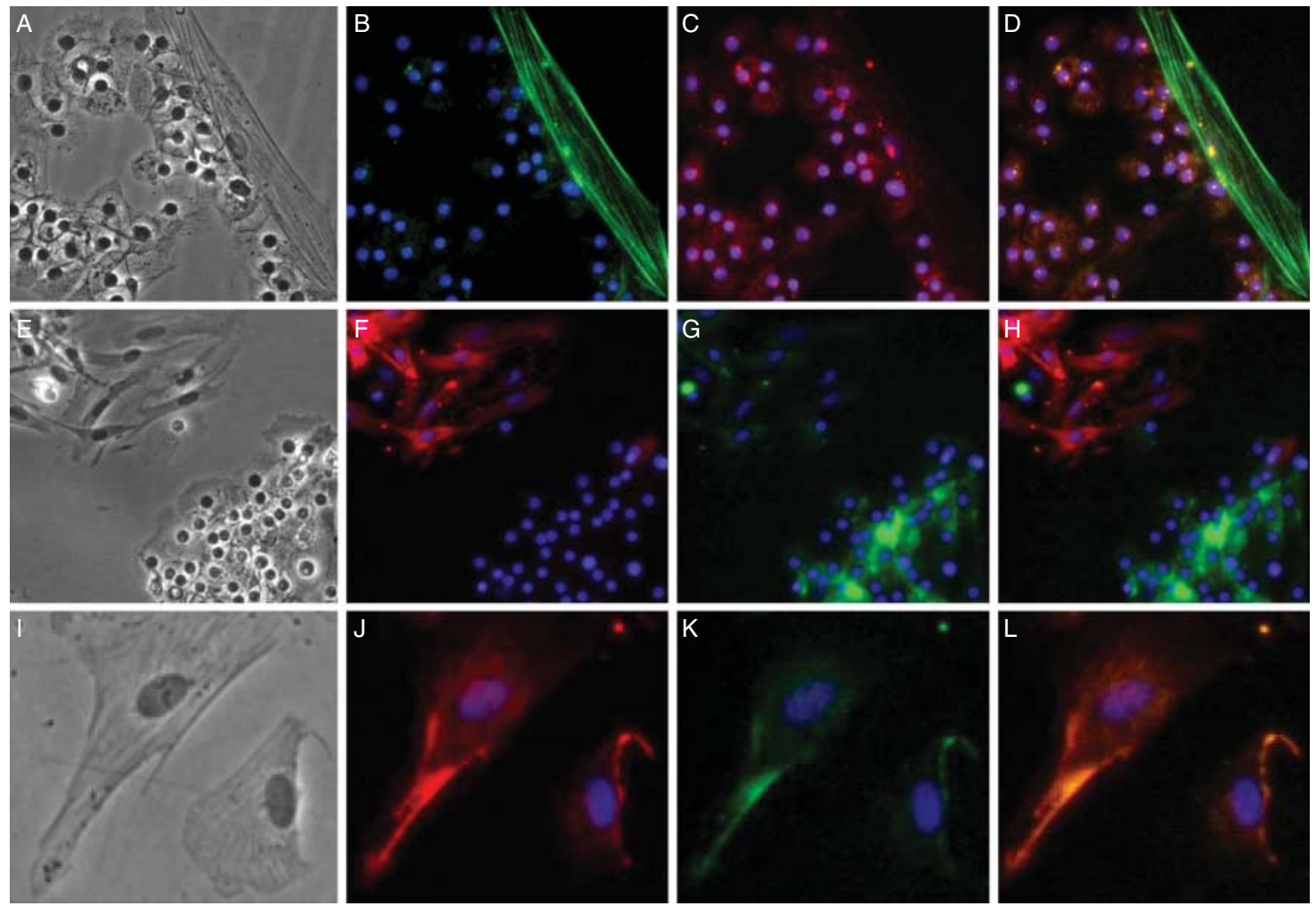

Figure 3

Characterisation of $\alpha$-SMA ${ }^{+}$cells from parathyroid adenomas. $\alpha$-SMA ${ }^{+}$ myofibroblasts derived from PAds did not express calcium-sensing receptor (CASR; A, B, C and D: $\alpha$-SMA, green; CASR, red) nor PTH (E, F, G and H:

have been demonstrated to express functional CASR, possibly involved in osteoblast differentiation (Ben Azouna et al. 2012). Treatment of hBM-MSCs with R568 $(50 \mu \mathrm{M})$ for 5 days in presence of $1.5 \mathrm{mM}$ extracellular calcium, a condition previously shown to activate CASR in cultured human parathyroid cells (Terranegra et al. 2010), induced a significant reduction in PTH mRNA levels in PAd-derived cells, as expected, and of VEGFA mRNA levels in hBM-MSCs. This effect was lost in long-term treatment, consistent with down-regulation of CASR. The increase in the VEGFA mRNA levels induced in hBM-MSCs by 5-10 days co-cultures with PAd-derived single cell preparations and explants was not affected by $50 \mu \mathrm{M}$ R568 (Fig. 5C).

\section{Effect of CXCL12-CXCR4 pathway blockade on PAd-stimulated VEGFA mRNA levels in hBM-MSCs}

Both hBM-MSCs and PAd-derived cells expressed the SDF1/CXCL12 receptor CXCR4 (Fig. 6A, a, b, c, d, e, f, g and $\mathrm{h})$. FACS analysis showed that $49-85 \%$ of
$\alpha$-SMA, red; PTH, green), two specific parathyroid cell genes. Indeed a subset of $\alpha-\mathrm{SMA}^{+}$cells co-expressed CD34 (K and L; $\alpha$-SMA, red; CD34, green).

SDF1/CXCL12 ${ }^{+}$cells co-expressed PTH $(n=3)$ (Fig. 6B), suggesting a potential crosstalk between hBM-MSCs and PAd-derived cells through the CXCL12-CXCR4 pathway. Treatment of hBM-MSCs co-cultured with PAd-derived explants with increasing concentrations of the antagonist of CXCR4 receptor AMD3100 blunted the increase in VEGFA mRNA expression levels induced by PAd-derived explants (Fig. 6C), while this effect was lost when hBM-MSCs were co-cultured with PAd-derived single cells.

\section{Role of the CXCL12/CXCR4 pathway in PAd-derived explants and single cells}

VEGFA mRNA levels were significantly higher in PAds ( $n=10 ; 4.2 \pm 0.9 ; P=0.008$ vs normal parathyroids) than that in normal parathyroid glands $(n=3 ; 0.4 \pm 0.2)$, while in PCas $(n=4 ; 3.5 \pm 1.6)$ VEGFA levels were similar to those found in normal glands.

We investigated the role of the CXCL12/CXCR4 pathway on VEGFA transcription regulation in parathyroid adenomatous cells. PAd-derived cells expressed

Published by Bioscientifica Ltd. 

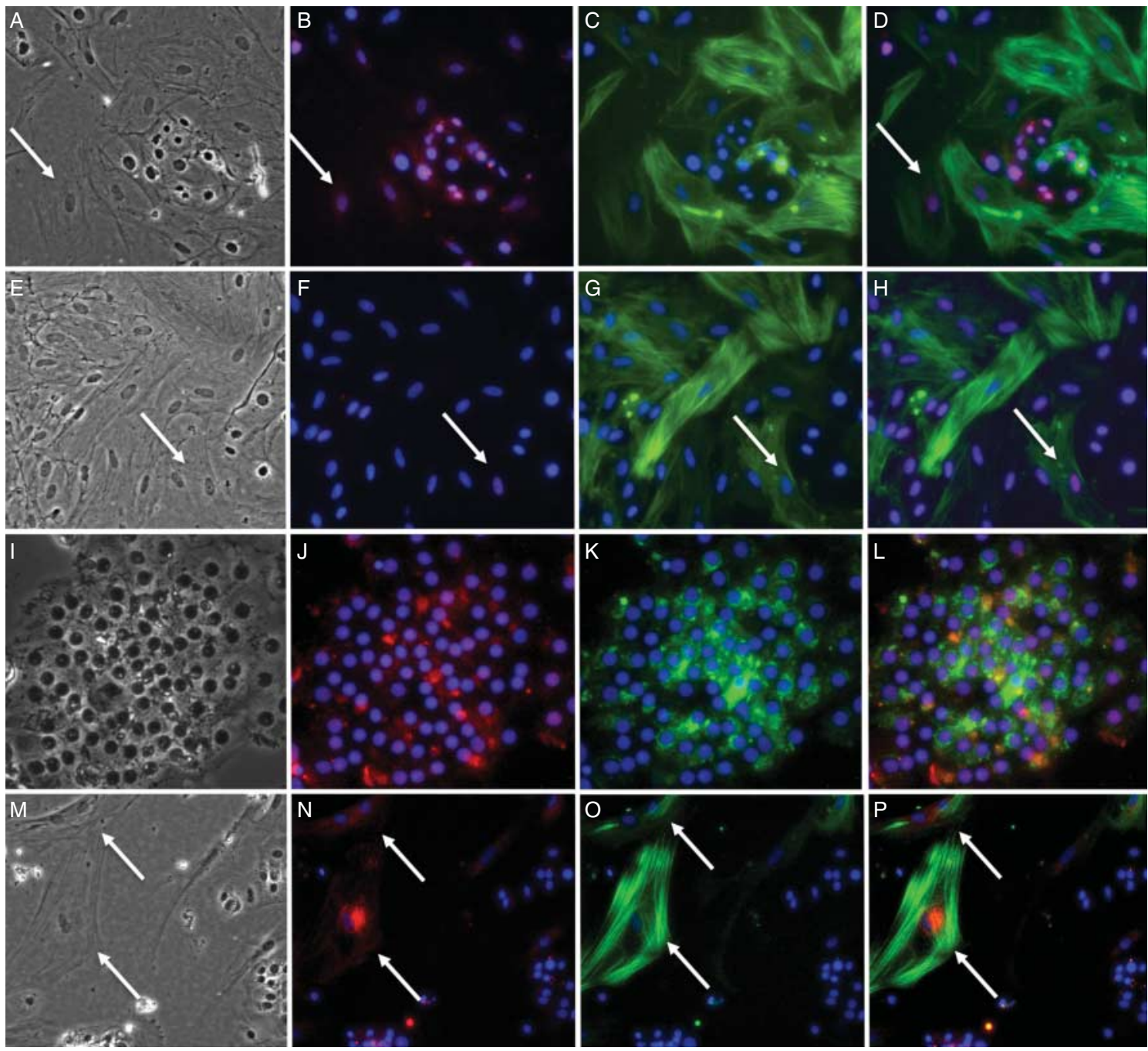

\section{Figure 4}

Tumour-associated $\alpha$-SMA ${ }^{+}$cells expressed parathyroid cells-specific transcription factors. Specific nuclear immunostaining for the transcription factor glial-cell missing 2 (GCM2) was detected in epithelial $\alpha$-SMAnegative parathyroid cells (A, B, C and D; $\alpha$-SMA, green; GCM2, red; arrows) as well as in $\alpha$-SMA ${ }^{+}$myofibroblasts $(E, F, G$ and $H ; \alpha$-SMA, green; GCM2,

CXCR4 (Fig. 7A) and FACS analysis identified a proportion of PAd-derived cells co-expressing PTH and CXCR4 of $29.7 \pm 11.5 \%$ of the whole tumour cells $(n=3$; Fig. 7B).

Increasing concentrations of AMD3100 induced no change in VEGFA mRNA expression levels in PAd-derived single cells as well as explants (data not shown). Nonetheless, AMD3100 determined a significant reduction in PTH mRNA expression levels in both cell preparations $(1.28 \pm 0.19$ in basal condition vs $0.86 \pm 0.07$ at $1 \mu \mathrm{g}$ in PAd-derived single cells and $1.05 \pm 0.14$ at $10 \mu \mathrm{g}$; in PAdderived explants, $2.07 \pm 0.62$ in basal condition vs $1.03 \pm$ 0.24 at $1 \mu \mathrm{g}$ and $1.13 \pm 0.15$ at $10 \mu \mathrm{g} ; P<0.05$ ) (Fig. $7 \mathrm{C}$ ). red; arrows). PAd-associated myofibroblasts showed also a positive nuclearspecific immunostaining for the transcription factor TBX1 ( $M, N, O$ and $P$; $\alpha$-SMA, green; TBX1, red; arrows); TBX1 nuclear staining (red) was observed also in $\mathrm{PTH}^{+}$(green) parathyroid epithelial cells (K and L). (A), (E), (K) and (M) showed contrast phase correspondent images.

\section{Discussion}

In this study we first investigated the stromal component of parathyroid neoplasia. Previous studies focused on the vascular component described increased density of microvessels in PAds and hyperplasia compared with the normal gland (Garcia de la Torre et al. 2004, Viacava et al. 2006). In this study, we report data supporting the presence of cells resembling the TAFs in parathyroid neoplasia. TAFs have been demonstrated to promote tumour development by cell-cell interaction or crosstalk with tumour cells through the secretion of growth factors, cytokines and chemokines

Published by Bioscientifica Ltd 
A
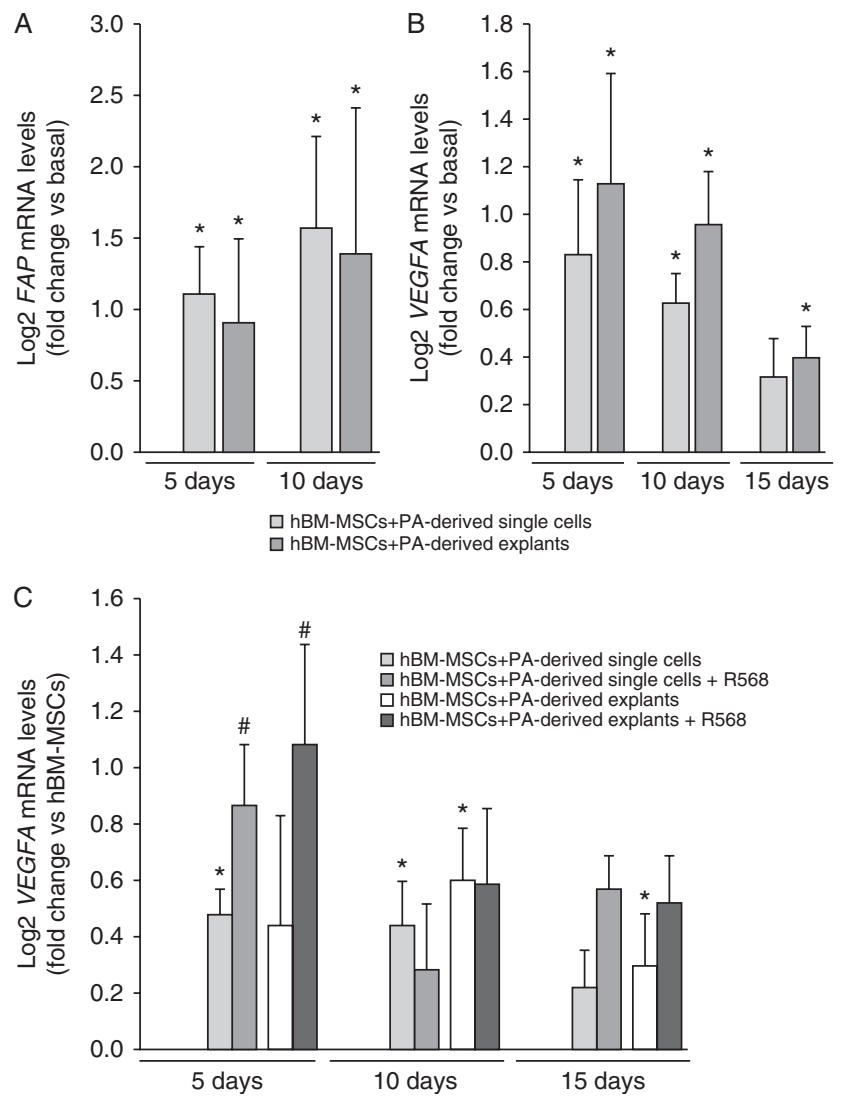

Figure 5

Gene expression variations in hBM-MSCs co-cultured with PAd-derived single cells and explants. (A) hBM-MSCs co-cultured with both PAd-derived single cells (light grey columns) and explants (dark grey columns) increased significantly the mRNA expression levels of $F A P$ both after 5 and 10 days of culture. (B) hBM-MSCs co-cultured with both PAd-derived single cells (light grey columns) and explants (dark grey columns) increased significantly the mRNA expression levels of VEGFA both after 5, 10 and 15 days of culture.

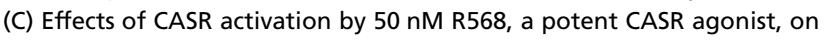
VEGFA mRNA expression levels in hBM-MSCs alone and co-cultured for 5 , 10 and 15 days with both PAd-derived single cells and explants. ${ }^{*} P<0.05$.

(Hanahan \& Coussens 2012). The acquisition of smooth muscle features by fibroblasts, most notably neo-formation of contractile stress fibres and expression of $\alpha$-SMA, is considered to be a central feature of activated stromal cells. We found that in normal parathyroid glands, the thin stroma surrounding parathyroid epithelial cells, arranged in acinar structures, was surprisingly enreached of $\alpha$-SMA ${ }^{+}$cells. In parathyroid tumours, $\alpha$-SMA ${ }^{+}$cells disappeared where the acinar structures were substituted by the monomorph sheet-like cell proliferation. Nonetheless, in typical PAds $\alpha$-SMA ${ }^{+}$cells constituted the wall of new microvessels that were particularly abundant. A similar pattern was detected in human foetal parathyroid glands. These findings suggest that 'perivascular' $\alpha$-SMA ${ }^{+}$ cells in PAds play a role in neoangiogenesis, at variance with 'periepithelial' $\alpha$-SMA ${ }^{+}$cells found in normal glands. By contrast, in malignant tumours, $\alpha$-SMA ${ }^{+}$cells were abundant in the stroma of fibrous bands and in the capsula and septa departing from the capsula, supporting a role of $\alpha$-SMA ${ }^{+}$cells in cancer invasiveness. PAts showed an intermediate pattern with $\alpha$-SMA ${ }^{+}$cells surrounding new vessels and abundant $\alpha$-SMA ${ }^{+}$cells in the capsula and septa stroma.

The stromal component of parathyroid tumours consisted of activated cells, as transcripts of FAP, which were absent in normal parathyroid glands, were detected at variable level in PAds and definitely increased in PCas. It is noteworthy that FAP expression characterises TAFs in epithelial-derived solid tumours (Kalluri \& Zeisberg 2006) and it is positively correlated with tumour cell proliferation, myofibroblasts content and blood vessels density (Santos et al. 2009).

Large spindle-shaped cells with cytoplasmic $\alpha$-SMA ${ }^{+}$ filaments resembling myofibroblasts, considered as a hallmark of activated fibroblasts, spread out from PAd-derived explants in short-term culture. A minority of explantsderived $\alpha$-SMA ${ }^{+}$cells co-expressed the cell surface marker CD34, supporting a contribution of BM progenitors to PAdassociated myofibroblasts origin. $\mathrm{CD} 34^{+}$endothelial progenitor cells has been reported to differentiate into both smooth muscle- and endothelial-like cells and to contribute to the development of vascular network (Guo et al. 2010). Interestingly, CD34 ${ }^{+}$cells expressing specific parathyroid genes have been previously identified in PAds (Corbetta et al. 2009). Moreover, $\alpha-\mathrm{SMA}^{+}$cells were negative for parathyroid-specific genes, such as CASR and $P T H$, while they occasionally co-expressed the parathyroidspecific transcription factors $G C M 2$ and $T B X 1$, suggesting the occurrence of epithelial-to-mesenchymal transition as a source of tumour-associated myofibroblasts (TAMs) in PAds. Based on these observations, parathyroid TAMs might be enrolled from resident myofibroblasts, or alternatively they might derive from BM progenitors or from epithelial-to-mesenchymal transition.

The hypothesis that PAd-derived epithelial cells are prone to 'activate' stromal cells was further investigated by co-culturing PAd-derived explants and single cells with hBM-MSCs. hBM-MSCs have been shown to transform into TAFs when co-cultured with breast cancers cells (Mishra et al. 2008, Spaeth et al. 2009). Therefore, considering the difficulty in obtaining fibroblasts from human parathyroid normal glands, hBM-MSCs were used as a surrogate. Both PAd-derived explant and single-cell preparations induced short- and long-term significant

Published by Bioscientifica Ltd 
A
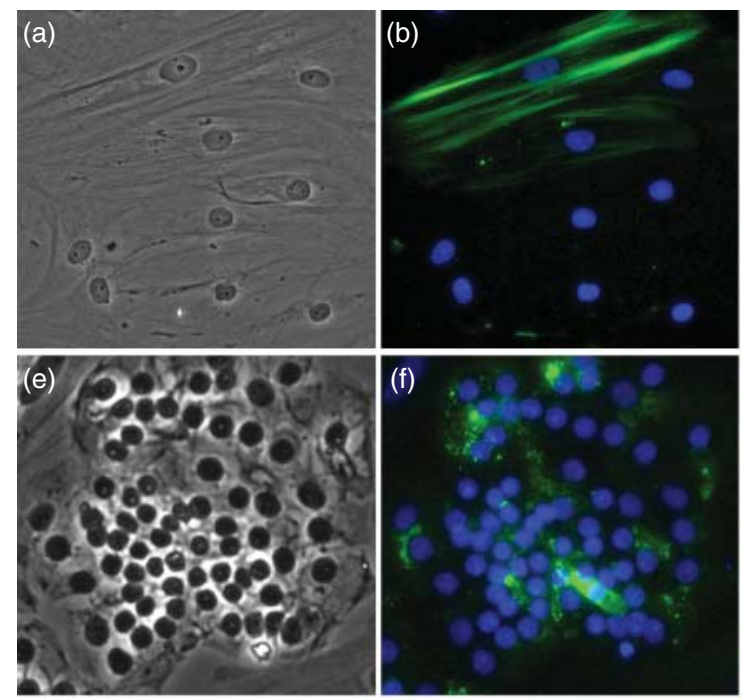
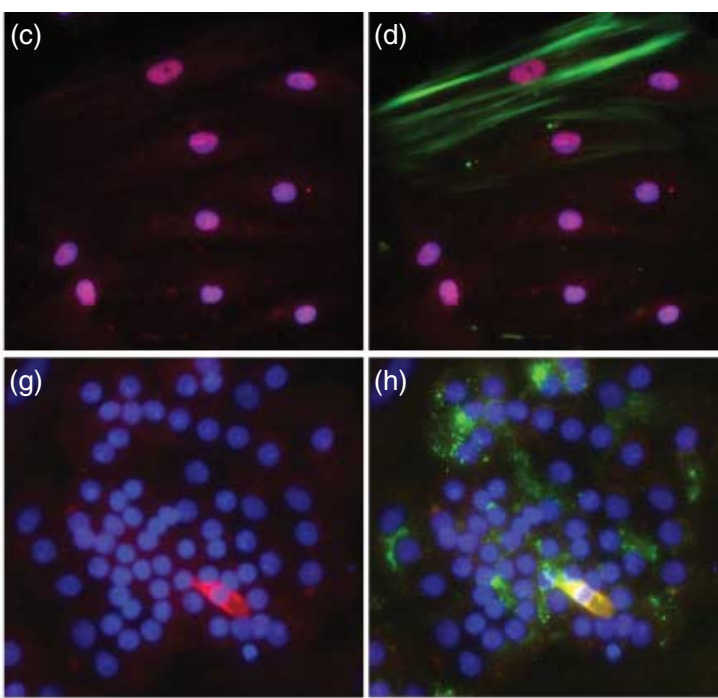

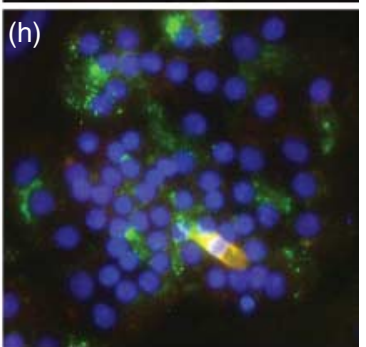

B

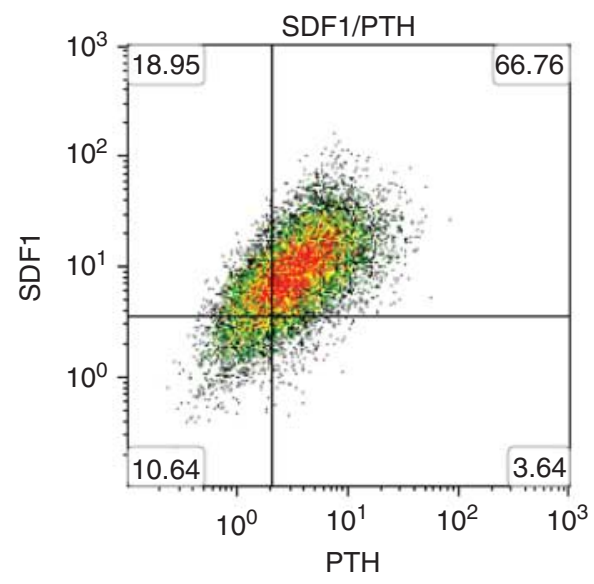

C

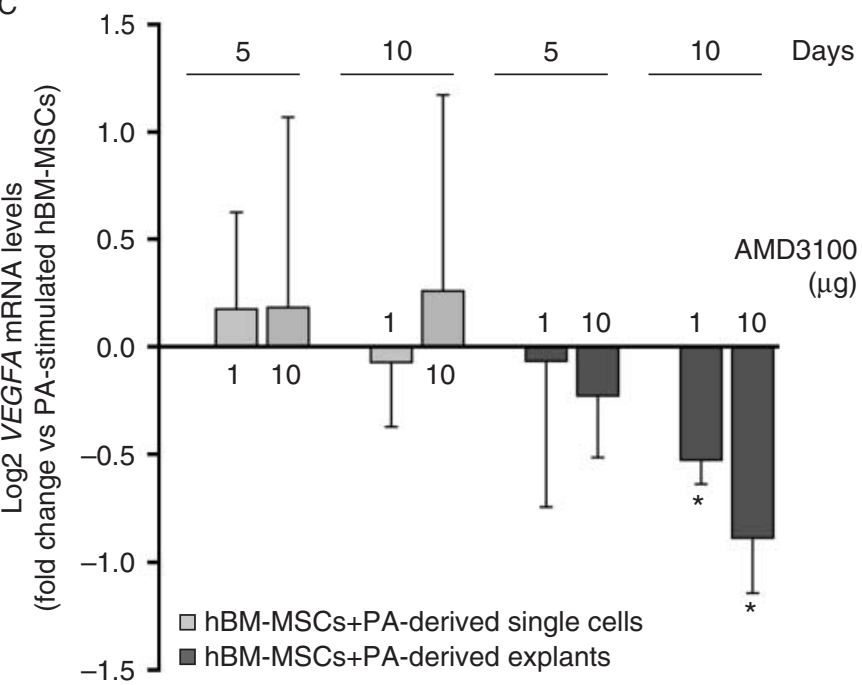

Figure 6

Role of the CXCL12/CXCR4 pathway on VEGFA gene expression changes in hBM-MSCs co-cultured with PAd-derived single cells and explants. (A) hBMMSC cells, a subset which co-expressed $\alpha$-SMA (green) and CXCR4 (red; $a, b$, c and d); PAd-derived cells co-expressing PTH (green) and CXCL12/SDF1

increases in FAP mRNA expression levels in hBM-MSCs. These data strongly suggest that hBM-MSCs were induced to express TAF-specific features by PAd-derived cells. Furthermore, VEGFA mRNA expression in hBM-MSCs was markedly stimulated by co-cultures, supporting the role of PAd-induced TAMs in neoangiogenesis. The crosstalk between hBM-MSCs and PAd-derived cells in modulating VEGFA mRNA expression in hBM-MSCs was unaffected by the treatment with the potent and selective CASR agonist R568, though both hBM-MSCs and (red; e, $f, g$ and $h$ ). (B and C) Effects of the CXCL12/CXCR4 blockade by increasing concentrations of AMD3100 on VEGFA mRNA expression levels in hBM-MSCs co-cultured with PAd-derived single cells and explants. $* P<0.05$

PAd-derived cells are known to express the CASR gene and protein.

The finding of a consistent proportion of both PAdderived $\mathrm{PTH}^{-}$and $\mathrm{PTH}^{+}$cells expressing SDF1/CXCL12 suggested an involvement of the CXCR4/CXCL12 pathway in parathyroid tumourigenesis. SDF1/CXCL12 has been demonstrated to play a central role in promotion of tumour growth and angiogenesis as it recruits endothelial progenitor cells into tumours, thereby furthering neoangiogenesis (Orimo \& Weinberg 2006). Treating co-cultures with

Published by Bioscientifica Ltd. 
A
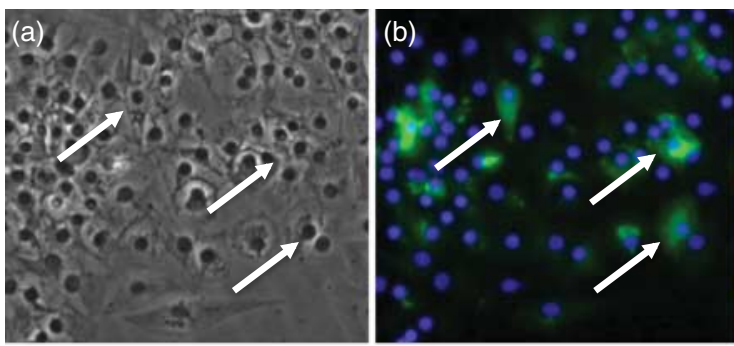

B

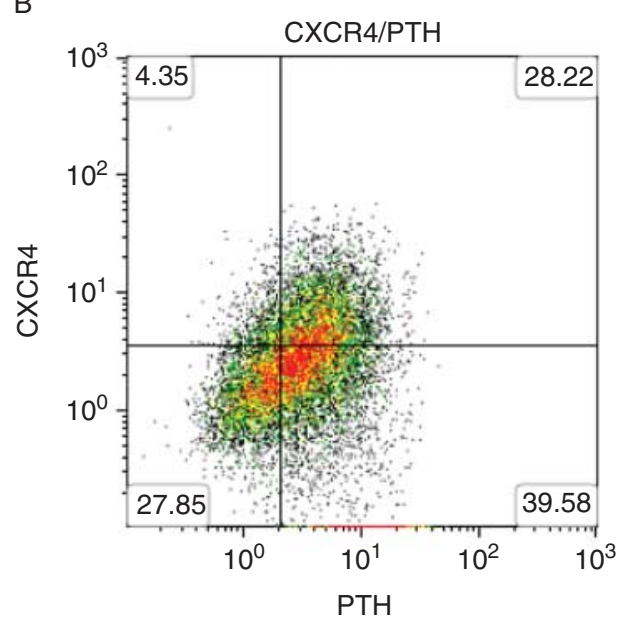

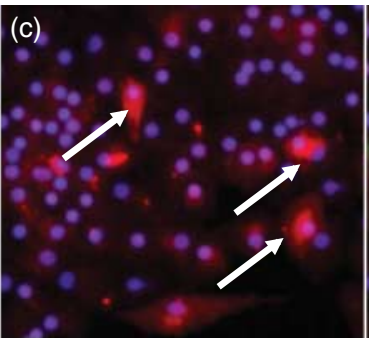

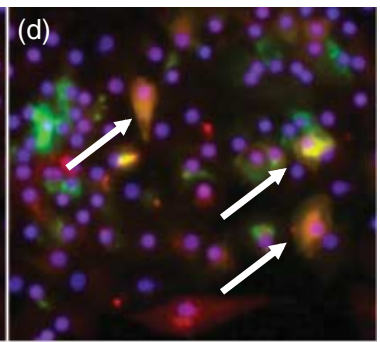

C

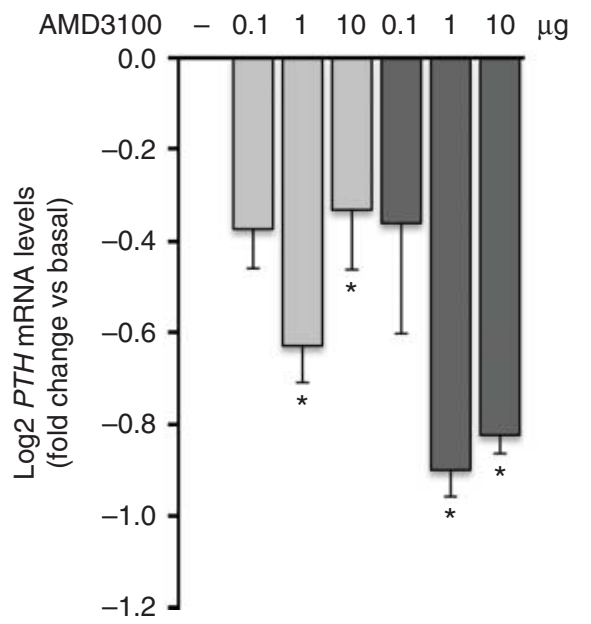

Figure 7

Effects of the CXCL12/CXCR4 pathway inhibition on PAd-derived explants and single cells. (A) Immunofluorescence showed that a subset of tumour parathyroid cells co-expressed PTH (green) and the SDF1/CXCL12-specific receptor CXCR4 (red) (a, b, c and d). (B) Representative FACS analysis

increasing concentrations of AMD3100, a small molecule inhibitor of CXCR4, significantly reduced the VEGFA expression levels stimulated by PAd-derived explants while it had no effect on VEGFA levels stimulated by PAd-derived single cells, suggesting that SDF1/CXCL12 derived from stromal cells rather than that derived from epithelial cells might stimulate VEGFA expression in hBM-MSCs.

VEGFA had been demonstrated to be essential to drive parathyroid-induced angiogenesis in a model of rat microvessels co-cultured with human parathyroid tissues (Carter et al. 2000). Indeed, we found a tenfold higher VEGFA levels in PAds than that in normal glands, though this observation was in contrast with a previous report (Garcia de la Torre et al. 2004). A proportion of the PAdderived $\mathrm{PTH}^{+}$cells also expressed CXCR4, the most common chemokine receptor overexpressed in human cancers (Gelmini et al. 2008), suggesting the existence of a paracrine/autocrine regulatory signalling in PAd-derived cells. However, CXCR4 blockade by AMD3100 in showing the proportion of PAd-derived cells co-expressing PTH and CXCR4. (C) Effects of AMD3100 on PAd-derived single cells and explants on PTH mRNA expression levels. ${ }^{*} P<0.05$.

PAd-derived cells has no effect on VEGFA mRNA levels. Finally, PTH mRNA levels were significantly inhibited by AMD3100. This finding might be attractive as AMD3100/ Plerixafor has been developed in clinical setting (Burger et al. 2011, Duda et al. 2011).

Though we are confident that our data might open new approaches to the investigation of parathyroid tumourigenesis, the study presented some limitations: i) isolation of pure stromal cells from parathyroid tumours were not performed due to the lack of TAF-specific markers; ii) experiments aimed to demonstrate the activating ability of the tumoral parathyroid cells could not be compared with parathyroid normal-derived cells and explants due to unavailability of normal glands biopsies and iii) analysis in PAts and PCas was limited by the small number of samples and by the FFPE sections as unique available material.

In conclusion, this is the first report suggesting that i) cells from benign tumours such as PAds show the ability

Published by Bioscientifica Ltd 
to activate cells of mesenchymal origin; ii) benign TAFs are involved in early tumoural neoangiogenesis; iii) CXCL12/CXCR4 pathway is expressed and active in parathyroid adenomatous cells and iv) CXCL12/CXCR4 might play a role in parathyroid tumour angiogenesis and PTH synthesis modulation and therefore it might be a target for new therapeutic approaches to patients with primary hyperparathyroidism.

\section{Declaration of interest}

The authors declare that there is no conflict of interest that could be perceived as prejudicing the impartiality of the research reported.

\section{Funding}

This work was supported by the Ricerca Corrente Funding of IRCCS Policlinico San Donato.

\section{References}

Ben Azouna N, Jenhani F, Regaya Z, Berraeis L, Ben Othman T, Ducrocq E \& Domenech J 2012 Phenotypical and functional characteristics of mesenchymal stem cells from bone marrow: comparison of culture using different media supplemented with human platelet lysate or fetal bovine serum. Stem Cell Research \& Therapy 3 6. (doi:10.1186/scrt97)

Bondenson L, Grimelius L, DeLellis RA, Lloyd R, Akerstrom G, Larsson C, Arnold A, Eng C, Shane E \& Bilezikian JP 2004 Parathyroid carcinoma. In Pathology and Genetics. Tumors of Endocrine Organs. WHO Classification of Tumors, pp 128-132. Eds RA DeLelli, RV Lloyd, PU Heitz \& C Eng. Lyon: IARC Press.

Burger JA, Stewart DJ, Wald O \& Peled A 2011 Potential of CXCR4 antagonists for the treatment of metastatic lung cancer. Expert Review of Anticancer Therapy 11 621-630. (doi:10.1586/era.11.11)

Carter WB, Uy K, Ward MD \& Hoying JB 2000 Parathyroid-induced angiogenesis is VEGF-dependent. Surgery 128 458-464. (doi:10.1067/ msy.2000.107102)

Corbetta S, Mantovani G, Lania A, Borgato S, Vicentini L, Beretta E, Faglia G, Di Blasio AM \& Spada A 2000 Calcium-sensing receptor expression and signaling in human parathyroid adenomas and primary hyperplasia. Clinical Endocrinology 52 339-348.

Corbetta S, Bulfamante G, Cortelazzi D, Barresi V, Cetin I, Mantovani G, Bondioni S, Beck-Peccoz P \& Spada A 2005 Adiponectin expression in human fetal tissues during mid- and late gestation. Journal of Clinical Endocrinology and Metabolism 90 2397-2402. (doi:10.1210/jc.2004-1553)

Corbetta S, Belicchi M, Pisati F, Meregalli M, Eller-Vainicher C, Vicentini L, Beck-Peccoz P, Spada A \& Torrente Y 2009 Expression of parathyroidspecific genes in vascular endothelial progenitors of normal and tumoral parathyroid glands. American Journal of Pathology $\mathbf{1 7 5}$ 1200-1207. (doi:10.2353/ajpath.2009.080979)

Corbetta S, Vaira V, Guarnieri V, Scillitani A, Eller-Vainicher C, Ferrero S, Vicentini L, Chiodini I, Bisceglia M, Beck-Peccoz P et al. 2010
Differential expression of microRNAs in human parathyroid carcinomas compared with normal parathyroid tissue. Endocrine-Related Cancer 17 135-146. (doi:10.1677/ERC-09-0134)

De Wever O, Demetter P, Mareel M \& Bracke M 2008 Stromal myofibroblasts are drivers of invasive cancer growth. International Journal of Cancer 123 2229-2238. (doi:10.1002/ijc.23925)

Duda DG, Kozin SV, Kirkpatrick ND, Xu L, Fukumura D \& Jain RK 2011 CXCL12 (SDF1 $\alpha$ )-CXCR4/CXCR7 pathway inhibition: an emerging sensitizer for anticancer therapies? Clinical Cancer Research 17 2074-2080. (doi:10.1158/1078-0432.CCR-10-2636)

Garcia de la Torre N, Buley I, Wass JAH, Hackson DG \& Turner HE 2004 Angiogenesis and lymphangiogenesis in parathyroid proliferative lesions. Journal of Clinical Endocrinology and Metabolism 89 2890-2896. (doi:10.1210/jc.2003-031651)

Gelmini S, Mangoni M, Serio M, Romagnani P \& Lazzeri E 2008 The critical role of SDF-1/CXCR4 axis in cancer and cancer stem cells metastasis. Journal of Endocrinological Investigation 31 809-819. (doi:10.1007/ BF03349262)

Guo S, Cheng Y, Ma Y \& Yang X 2010 Endothelial progenitor cells derived from CD $34^{+}$cells form cooperative vascular networks. Cellular Physiology and Biochemistry 26 679-688. (doi:10.1159/000322335)

Hanahan D \& Coussens LM 2012 Accessories to the crime: functions of cells recruited to the tumor microenvironment. Cancer Cell 21 309-322. (doi:10.1016/j.ccr.2012.02.022)

Kalluri R \& Zeisberg M 2006 Fibroblasts in cancer. Nature Reviews. Cancer 6 392-401. (doi:10.1038/nrc1877)

Kojima Y, Acar A, Eaton EN, Mellody KT, Scheel C, Ben-Porath I, Onder TT, Wang ZC, Richardson AL, Weinberg RA et al. 2010 Autocrine TGF- $\beta$ and stromal cell-derived factor-1 (SDF-1) signaling drives the evolution of tumor-promoting mammary stromal myofibroblasts. PNAS 107 20009-20014. (doi:10.1073/pnas.1013805107)

Mishra PJ, Mishra PJ, Humeniuk R, Medina DJ, Alexe G, Mesirov JP, Ganesan S, Glod JW \& Benerjee D 2008 Carcinoma-associated fibroblast-like differentiation of human mesenchymal stem cells. Cancer Research 68 4331-4339. (doi:10.1158/0008-5472.CAN-08-0943)

Orimo A \& Weinberg RA 2006 Stromal fibroblasts in cancer, a novel tumor promoting cell type. Cell Cycle 15 1597-1601. (doi:10.4161/cc. 5.15.3112)

Polanska UM \& Orimo A 2013 Carcinoma-associated fibroblasts: nonneoplastic tumour-promoting mesenchymal cells. Journal of Cellular Physiology 228 1651-1657. (doi:10.1002/jcp.24347)

Santos AM, Jung J, Aziz N, Kissil JL \& Purè E 2009 Targeting fibroblast activation protein inhibits tumor stromagenesis and growth in mice. Journal of Clinical Investigation 119 3613-3625. (doi:10.1172/JCI38988)

Spaeth EK, Dembiski JL, Sasser AK, Watson K, Klopp A \& Hall B 2009 Mesenchymal stem cell transition to tumor-associated fibroblasts contributes to fibrovascular network expansion and tumor progression. PLoS ONE 4 e4992, 1-11. (doi:10.1371/journal.pone.0004992)

Terranegra A, Ferraretto A, Dogliotti E, Scarpellini M, Corbetta S, Barbieri AM, Spada A, Arcidiacono T, Rainone F, Aloia A et al. 2010 Calcimimetic R-568 effects on activity of R990G polymorphism of calcium-sensing receptor. Journal of Molecular Endocrinology 45 245-256. (doi:10.1677/ JME-10-0034)

Viacava P, Bocci G, Fanelli G, Cetani F, Marcocci C, Bevilacqua G \& Naccarato AG 2006 Microvessel density in human normal and neoplastic parathyroids. Endocrine Pathology 17 175-181. (doi:10.1385/EP:17:2:175)

Received in final form 13 December 2014

Accepted 16 December 2014

Made available online as an Accepted Preprint

16 December 2014 http://erc.endocrinology-journals.org DOI: 10.1530/ERC-14-0161
(C) 2015 Society for Endocrinology Printed in Great Britain 